\title{
A concept for stimulated proton transfer in 1-(phenyldiazenyl)naphthalen-2-ols
}

Hristova, Silvia ; Deneva, V; Pittelkow, Michael ; Crochet, Aurelien ; Kamounah, Fadhil S.; Fromm, Katharina M. ; Hansen, Poul Erik; Antonov, Liudmil

Published in:

Dyes and Pigments

DOI:

10.1016/j.dyepig.2018.03.070

Publication date:

2018

Document Version

Peer reviewed version

Citation for published version (APA):

Hristova, S., Deneva, V., Pittelkow, M., Crochet, A., Kamounah, F. S., Fromm, K. M., Hansen, P. E., \& Antonov, L. (2018). A concept for stimulated proton transfer in 1-(phenyldiazenyl)naphthalen-2-ols. Dyes and Pigments, 156(September), 91-99. https://doi.org/10.1016/j.dyepig.2018.03.070

\section{General rights}

Copyright and moral rights for the publications made accessible in the public portal are retained by the authors and/or other copyright owners and it is a condition of accessing publications that users recognise and abide by the legal requirements associated with these rights.

- Users may download and print one copy of any publication from the public portal for the purpose of private study or research.

- You may not further distribute the material or use it for any profit-making activity or commercial gain.

- You may freely distribute the URL identifying the publication in the public portal.

Take down policy

If you believe that this document breaches copyright please contact rucforsk@kb.dk providing details, and we will remove access to the work immediately and investigate your claim. 


\section{Accepted Manuscript}

A concept for stimulated proton transfer in 1-(phenyldiazenyl)naphthalen-2-OLS

S. Hristova, V. Deneva, M. Pittelkow, A. Crochet, F.S. Kamounah, K.M. Fromm, P.E. Hansen, L. Antonov

\section{OHE

PII:

S0143-7208(18)30216-X

DOI:

10.1016/j.dyepig.2018.03.070

Reference: DYPI 6655

To appear in: Dyes and Pigments

Received Date: 29 January 2018

Revised Date: 7 March 2018

Accepted Date: 29 March 2018

Please cite this article as: Hristova S, Deneva V, Pittelkow M, Crochet A, Kamounah FS, Fromm KM, Hansen PE, Antonov L, A concept for stimulated proton transfer in 1-(phenyldiazenyl)naphthalen-2-OLS, Dyes and Pigments (2018), doi: 10.1016/j.dyepig.2018.03.070.

This is a PDF file of an unedited manuscript that has been accepted for publication. As a service to our customers we are providing this early version of the manuscript. The manuscript will undergo copyediting, typesetting, and review of the resulting proof before it is published in its final form. Please note that during the production process errors may be discovered which could affect the content, and all legal disclaimers that apply to the journal pertain. 


\title{
A CONCEPT FOR STIMULATED PROTON TRANSFER IN 1-
}

\section{(PHENYLDIAZENYL)NAPHTHALEN-2-OLS}

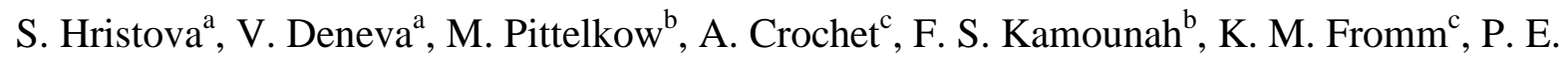
Hansen $^{\text {d }}$ L. Antonov ${ }^{\mathrm{a}}$

${ }^{a}$ Institute of Organic Chemistry with Centre of Phytochemistry, Bulgarian Academy of Sciences, Acad. G. Bonchev str., bl. 9, 1113 Sofia, Bulgaria

${ }^{\mathrm{b}}$ University of Copenhagen, Department of Chemistry, Universitetsparken 5, DK-2100 Copenhagen, Denmark

${ }^{c}$ University of Fribourg, Department of Chemistry, Chemin du Musée 9, CH-1700 Fribourg, Switzerland

${ }^{\mathrm{d}}$ Roskilde University, Department of Science and Environment, Roskilde, DK-4000, Denmark

\begin{abstract}
:
A series of aryl azo derivatives of naphthols (1-3) were studied by means of UV-Vis and NMR spectroscopy in different solvents as well as by quantum chemical calculations and $\mathrm{X}$ ray analysis. Previous studies have shown that Sudan 1 (1) exists as a tautomeric mixture. The effect of the solvents is minimized by the existing intramolecular hydrogen bond. Therefore, the influence on the tautomeric state in structurally modified $\mathbf{1}$ has been investigated. Structure 2 contains an additional OH-group, which deprotonates easily and affects the position of the tautomeric equilibrium by changing the electronic properties of the substituent. The implementation of a sidearm in $\mathbf{3}$ creates a condition for competition between the nitrogen from the azo group and from the piperidine unit for the tautomeric proton. In this case the use of acid as a stimulus for controlling the tautomeric process was achieved.
\end{abstract}

Keywords: tautomerism, molecular switches, molecular spectroscopy, azo dyes 


\section{Introduction:}

Aromatic azo derivatives are one of the largest and the most important classes of colorants. Their practical and theoretical importance has been reflected in textiles, food, paper printing, nonlinear optical (NLO) devices and liquid crystalline displays (LCDs) [1]. Most of the azodyes are tautomeric ones, and therefore the study of their tautomerism is of practical and fundamental significance. Moreover, some structurally modified tautomeric azonaphthols are recently considered as a promising prototype compounds for the development of new systems, exploiting controlled proton transfer for signal conversion and for use in molecular electronics [2]. This can be achieved by implementing an antenna - host (crown ethers or similar macrocyclic receptors), which transfers the signal from external stimuli to the tautomeric backbone [3,4]. In such a way, the change in the tautomeric state results from appearance/disappearance of the external stimuli. The sensitivity of the electronic ground and excited states of the tautomeric forms to the environment stimuli (light, $\mathrm{pH}, \mathrm{T}$, solvents), and to the presence of a variety of substituents or hydrogen bonding motifs are used as tools to tune the expected action. Our previous studies on 4-(phenyldiazenyl)naphthalen-1-ol derivatives, in which a side moiety is connected to a tautomeric unit [4], showed that, when the tautomeric proton becomes part of a stabilizing, intramolecular hydrogen-bonding system, a full shift of the tautomeric equilibrium to the enol form is achieved. In such compounds controlled shift in the position of the tautomeric equilibrium can be accomplished through protonation/deprotonation or complexation. In these systems, the tautomeric proton is transferred through a long distance, which makes it very sensitive to the solvent used. Therefore, it is interesting to see how the antenna could behave, when the proton exchanges through intramolecular hydrogen bonds within the tautomeric unit.

Sudan I (1-(phenyldiazenyl)naphthalene-2-ol), the most intensively used azo dye [5,6], is a typical example for the effect of the intramolecular hydrogen bonding on the proton transfer. Previous studies have shown that Sudan I (1) always exists as a tautomeric mixture in solution $[7,8]$. Having in mind that the specific effects of the solvents are minimized by the existing intramolecular hydrogen bond, the solvent polarity plays an important role - in non-polar solvents such as $i$-octane and tetrachloromethane 1a (enol, azo) form predominates, while in more polar solvents (like methanol) the opposite effect is observed and form $\mathbf{1 b}$ (ketohydrazo) prevails (Scheme1).

The aim of this study is to investigate how structural modifications in $\mathbf{1}$ can influence its tautomerism. Structure $\mathbf{2}$ contains an additional $\mathrm{OH}$-group which is expected to deprotonate 
easily and to affect the position of the tautomeric equilibrium by changing the electronic properties of the substituent (from $\mathrm{OH}$ to $\mathrm{O}^{-}$). The implementation of a sidearm in the newly synthesized compound $\mathbf{3}$ creates conditions for a competition between the nitrogen atom from the azo group and the nitrogen atom from the piperidine unit (3a vs. 3a', Scheme 2) for the tautomeric proton. The overall idea is to investigate if these modifications could provide possibilities for controlling the tautomeric equilibrium in the backbone of $\mathbf{1}$ in solution. The investigations were performed by using UV-VIS and NMR spectroscopy in various solvents, quantum-chemical calculations and crystallographic analysis.

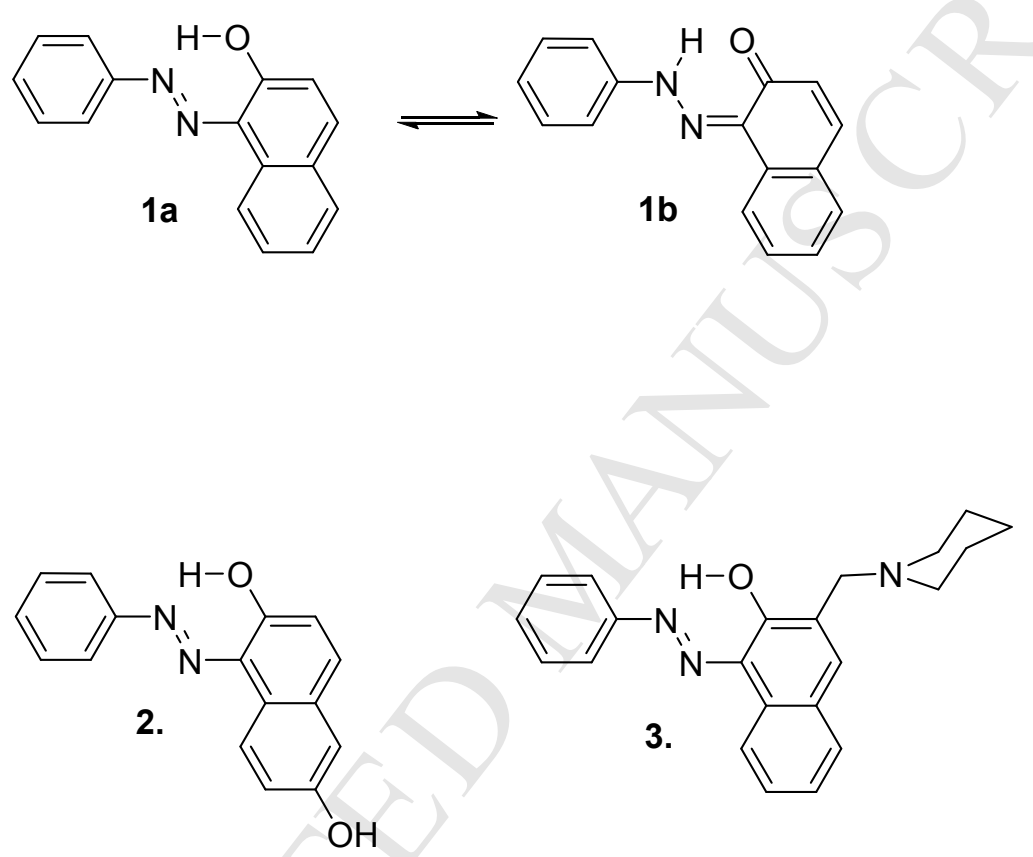

Scheme 1. Tautomeric equilibrium in $\mathbf{1}$ and structures of the investigated compounds $\mathbf{2}$ and $\mathbf{3}$.

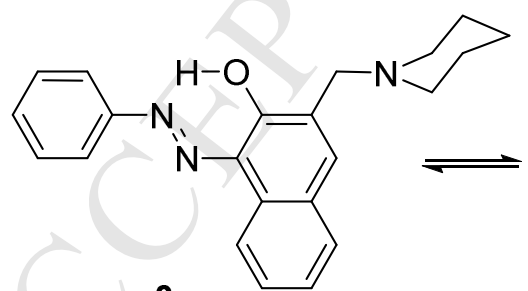

$3 a$

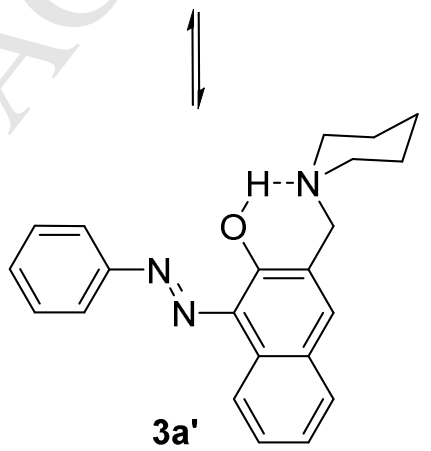

3b

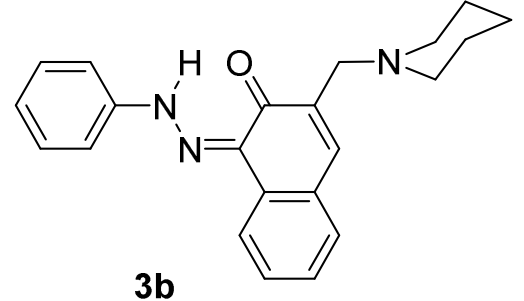




\section{Experimental part:}

Compounds. 3-Hydroxy-2-naphthoic acid $\mathbf{A}$ and 2,6-dihydroxynapthalene were purchased from TCI research chemicals. All other reagents and solvents were analytical grades purchased from Sigma-Aldrich Chemical Co. and used as received unless otherwise stated. Fluka silica gel /TLC-cards 60778 with fluorescence indicator $254 \mathrm{~nm}$ were used for TLC chromatography. Merck silica gel $60(0.040-0.063 \mathrm{~mm})$ was used for flash chromatography purification of the products. The HRMS LC/MS experiments were carried out on a Bruker MicrOTOF-QII-system with ESI-source with nebulizer 1.2 bar, dry gas $8.0 \mathrm{l} / \mathrm{min}$, dry temperature $200{ }^{\circ} \mathrm{C}$, capillary $4500 \mathrm{~V}$ and end plate offset $-500 \mathrm{~V}$.

\subsection{Synthesis}

1-(Phenyldiazenyl)naphthalen-2-ol 1:

A solution containing of aniline $(0.93 \mathrm{~g}, 10 \mathrm{mmol})$ and concentrated $\mathrm{HCl}(5.0 \mathrm{ml})$ in distilled water $(25.0 \mathrm{ml})$ was stirred at $0-5^{\circ} \mathrm{C}$ for 30 minutes. To this solution was added slowly a cold solution of sodium nitrite $(0.83 \mathrm{~g}, 12 \mathrm{mmol})$ in distilled water $(10.0 \mathrm{ml})$ and the mixture left stirred at $0-5^{\circ} \mathrm{C}$ for 45 minutes. The diazonium salt solution was then added dropwise with vigorous stirring over 25 minutes to a solution of 2-naphthol $(1.5 \mathrm{~g}, 10.05 \mathrm{mmol})$, sodium hydroxide $(0.8 \mathrm{~g}, 20 \mathrm{mmol})$ in distilled water $(50.0 \mathrm{ml})$ maintained at $0-5^{\circ} \mathrm{C}$. After complete addition, the mixture stirred in cold for 45 minutes and $1 \mathrm{~h}$ at room temperature, and then acidified with $6 \mathrm{M} \mathrm{HCl}$ to $\mathrm{pH} 2-3$. The red precipitate was collected and washed with water until neutral. The solid was dried in vacuum at room temperature and recrystallized three times from absolute ethanol $(15 \mathrm{ml})$ to give red needles $(1.96 \mathrm{~g}, 76 \%)$. The NMR data are consistent with that reported in literature [9]. HRMS-ESI calculated for $\mathrm{C}_{16} \mathrm{H}_{13} \mathrm{~N}_{2} \mathrm{O}(\mathrm{M}+\mathrm{H})^{+}$ 249.10279 , found 249.10252.

\section{1-(Phenyldiazenyl)naphthalene-2,6-diol 2:}

A solution containing aniline $(1.02 \mathrm{~g}, 11 \mathrm{mmol})$ and concentrated $\mathrm{HCl}(3.25 \mathrm{ml})$ in distilled water $(5.0 \mathrm{ml})$ was stirred at $0-5^{\circ} \mathrm{C}$ for 30 minutes. To this solution was added slowly an icecold solution of sodium nitrite $(0.77 \mathrm{~g}, 11 \mathrm{mmol})$ in distilled water $(5.0 \mathrm{ml})$ and the mixture left stirred at $0-5{ }^{\circ} \mathrm{C}$ for 45 minutes. The diazonium salt solution was then added dropwise with vigorous stirring over 30 minutes to a solution of 2,6-dihydroxynaphthalene $(1.76 \mathrm{~g}, 11$ mmol) in $10 \%$ aqueous sodium hydroxide $(9.15 \mathrm{ml})$ ) maintained at $0-5^{\circ} \mathrm{C}$. After complete 
addition, the mixture stirred in the cold for 45 minutes and then $1 \mathrm{~h}$ at room temperature. The red precipitate was treated with distilled water $(50.0 \mathrm{ml})$ and filtered, the solid washed with water until neutral and the red solid residue dried in vacuum at room temperature. The crude product was purified by flash column chromatography on silica gel with dichloromethane/ethyl acetate (10:1) and recrystallization from $75 \%$ aqueous ethanol $(12 \mathrm{ml})$ to obtain 2 as a dark-red solid $(0.89 \mathrm{~g}, 31 \%)$ as a dark- red solid. ${ }^{1} \mathrm{H}$ NMR (DMSO-d 6,400 MHz) $\delta 15.59$ (s, XH), 9.77 (bs, OH-6), 8.36 (d, H-8, $J=8.8$ Hz), 7.81 (d, H-4, J =9.6), 7.80 (d, H-2'.H-6', $J=7.7$ ), 7.52 (“'t”, H-3',H-5', $J=7.7$ and $J=8.1 \mathrm{~Hz}$ ), 7.33 (t, H-4', $J=7.3 \mathrm{~Hz}$ ), $7.10(\mathrm{~d}, \mathrm{~d}, \mathrm{H}-7, J=2.5$ and $J=8.8 \mathrm{~Hz}), 7.08(\mathrm{~d}, \mathrm{H}-5, J=2.4 \mathrm{~Hz}), 6.82(\mathrm{~d}, \mathrm{H}-3, J=9.4 \mathrm{~Hz}) .{ }^{13} \mathrm{C}$ NMR data are given in Table 1. HRMS-ESI calculated for $\mathrm{C}_{16} \mathrm{H}_{13} \mathrm{~N}_{2} \mathrm{O}_{2}\left(\mathrm{M}^{+} \mathrm{H}\right)^{+}$265.09770, found 265.09783 .

Table $1 .{ }^{13} \mathrm{C}$ chemical shifts of compounds 1-3. The numbering is shown in Scheme 3.

\begin{tabular}{|c|c|c|c|c|c|c|}
\hline $\begin{array}{l}\text { Carbon/ } \\
\text { Compounds }\end{array}$ & $\begin{array}{c}\mathbf{1}^{\mathrm{a}} \\
\mathrm{CDCl}_{3}\end{array}$ & $\begin{array}{c}1 \\
\text { DMSO-d }_{6}\end{array}$ & $\begin{array}{c}\mathbf{2} \\
\text { Acetonitril-d }\end{array}$ & $\begin{array}{c}2 \\
\text { DMSO- }_{6}\end{array}$ & $\begin{array}{c}\mathbf{3}^{\mathrm{b}} \\
\mathrm{CDCl}_{3}\end{array}$ & $\begin{array}{c}3^{\mathrm{e}} \\
\text { DMSO-d }_{6}\end{array}$ \\
\hline $\mathrm{C}-1$ & 129.67 & 129.17 & 130.20 & 129.26 & 129.95 & 129.58 \\
\hline $\mathrm{C}-2$ & 171.56 & 168.77 & 169.74 & 169.97 & 174.80 & 173.40 \\
\hline $\mathrm{C}-3$ & 124.48 & 123.89 & 125.20 & 124.54 & $\mathrm{~m}^{\mathrm{c}}$ & $\mathrm{m}^{\mathrm{c}}$ \\
\hline $\mathrm{C}-4$ & 139.64 & 139.92 & 139.66 & 140.00 & $144.09 \mathrm{br}^{\mathrm{d}}$ & $\mathrm{m}^{\mathrm{c}}$ \\
\hline C-4a & 127.71 & 127.80 & 127.32 & 129.68 & 127.49 & 126.92 \\
\hline $\mathrm{C}-5$ & 128.27 & 129.07 & 112.81 & 112.48 & 129.71 & 128.99 \\
\hline C-6 & 125.35 & 125.81 & 155.78 & 155.83 & 126.43 & 126.32 \\
\hline $\mathrm{C}-7$ & 128.48 & 128.87 & 119.26 & 119.05 & 129.90 & 129.27 \\
\hline $\mathrm{C}-8$ & 121.44 & 121.28 & 123.95 & 123.13 & 121.61 & 121.20 \\
\hline $\mathrm{C}-8 \mathrm{a}$ & 133.26 & 132.73 & $\mathrm{~m}^{\mathrm{c}}$ & 125.35 & 133.84 & 132.98 \\
\hline $\mathrm{C}-1^{\prime}$ & 144.44 & 145.08 & 146.23 & 144.73 & 143.47 & 143.08 \\
\hline $\mathrm{C}-2^{\prime}$ & 118.26 & 118.93 & 119.32 & 118.2 & 118.13 & 117.91 \\
\hline $\mathrm{C}-3^{\prime}$ & 129.23 & 129.79 & 130.26 & 129.74 & 129.90 & 129.87 \\
\hline C-4' & 127.03 & 128.06 & 128.05 & 127.19 & 127.32 & 127.20 \\
\hline
\end{tabular}

a Assignment according to [9]; b The resonances for $\mathrm{CH}_{2}$ and the piperidine ring, $54.53 \mathrm{ppm}, 53.90$ ppm, 24.43 ppm, 23.33 ppm; c Missing; d br means broad; e The resonances for $\mathrm{CH}_{2}$ and the piperidine ring, 54 ppm (br), 52.97 ppm, 23.65 ppm, 22.07 ppm. 


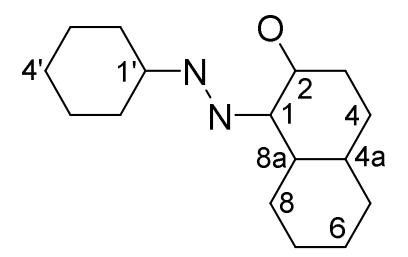

Scheme 3. Numbering of the tautomeric backbone.

Compound $\mathbf{3}$ was synthesized in three steps starting with 3-hydroxy-2-naphthoic acid $\mathbf{A}$ as shown in Scheme 4.

Step 1: 3-Hydroxy-2-naphthoic acid-N-piperidinylamide B:

A solution of 3-hydroxy-2-naphthoic acid $(6.18 \mathrm{~g}, 32 \mathrm{mmol})$ in dry dichloromethane $(250 \mathrm{ml})$ was treated with 8 drops of dry DMF followed by slow addition of oxalyl chloride $(8.6 \mathrm{ml}$, $98.4 \mathrm{mmol})$. The reaction mixture was stirred at $25^{\circ} \mathrm{C}$ under nitrogen atmosphere for $24 \mathrm{~h}$. The solvent was evaporated under reduced pressure and the crude solid residue was diluted with dry dichloromethane $(75 \mathrm{ml})$ and dry THF $(75 \mathrm{ml})$ and the solution was stirred at $0^{\circ} \mathrm{C}$ for 20 minutes under a nitrogen atmosphere. A 2 M solution of piperidine in THF (49.2 ml) was added dropwise and the heterogeneous mixture left stirred at $25^{\circ} \mathrm{C}$ under nitrogen atmosphere for $72 \mathrm{~h}$. The white solid was filtered and the filtrate evaporated under reduced pressure to afford a crude amber solid. This was purified by flash column chromatography on silica gel with dichloromethane/ethyl acetate (10:1) to obtain the amide compound $\mathbf{B}$ as a white solid $(6.2 \mathrm{~g}, 74 \%)$ as a white solid. The ${ }^{1} \mathrm{H} \mathrm{NMR}\left(\mathrm{CDCl}_{3}, 500 \mathrm{MHz}\right)$ data are consistent with that reported in literature [10] ${ }^{13} \mathrm{C} \mathrm{NMR}\left(\left(\mathrm{CDCl}_{3}, 126 \mathrm{HMz}\right) \delta 170.2(\mathrm{CO}), 154.6(\mathrm{C}-3) 135.9(\mathrm{C}-\right.$ 4a), 128.7 C-5 or C-8), 128.5 (C-5 or C-8), 128.0 (C-4a) 127.0 (C-6 or C-7), 124.1 (C-6 or C7), 120.4 (C-2), 112.3 (C-4), 26.3, 24.7. HRMS-ESI calculated for $\mathrm{C}_{16} \mathrm{H}_{18} \mathrm{NO}_{2}(\mathrm{M}+\mathrm{H})^{+}$ 256.09770, found 256.09762.

Step 2: 3-(1-Piperidinylmethyl)naphthalen-2-ol C:

A solution of the amide B (1.84 g, $7.2 \mathrm{mmol})$ in dry THF (35 ml) was added dropwise under nitrogen atmosphere to a suspension of $\mathrm{LiAlH}_{4}(0.56 \mathrm{~g}, 14.7 \mathrm{mmol})$ in dry THF at $0^{\circ} \mathrm{C}$ with vigorous stirring. After complete addition, the mixture stirred at $25^{\circ} \mathrm{C}$ for 15 minutes and then refluxed under nitrogen atmosphere for $2 \mathrm{~h}$. Cooled to $0^{\circ} \mathrm{C}$ and quenched with saturated 
aqueous potassium fluoride solution $(20 \mathrm{ml})$. The product was then extracted with dichloromethane $(3 \times 50 \mathrm{ml})$, washed with brine and dried over anhydrous magnesium sulphate. Filtration and subsequent evaporation of solvent under reduced pressure afforded a solid residue, that was purified by flash column chromatography on silica gel with dichloromethane/n-heptane (2:1) and finally with dichloromethane to obtain compound $\mathbf{C}$ as a white solid (1.4 g, 82\%). ${ }^{1} \mathrm{H} \mathrm{NMR}\left(\mathrm{CDCl}_{3}, 500 \mathrm{MHz}\right) \delta 11.23$ (broad s, $\left.1 \mathrm{H}\right), 7.57-7.55$ (m, $2 \mathrm{H}), 7.37(\mathrm{~d}, 1 \mathrm{H} J=8.2 \mathrm{~Hz}), 7.26(\mathrm{t}, 1 \mathrm{H} J=7.4 \mathrm{~Hz}), 7.15(\mathrm{t}, 1 \mathrm{H} J=7.4 \mathrm{~Hz}), 7.07(\mathrm{~s}, 1 \mathrm{H}) .{ }^{13} \mathrm{C}$ NMR ( $\left.\mathrm{CDCl}_{3}, 126 \mathrm{MHz}\right) \delta 156.3$ (C-2), $\left.134.6 \mathrm{C}-8 \mathrm{a}\right), 128.1$ (C-4a), $\left.127.8 \mathrm{C}-8\right), 127.4$ (C-5), 126.3 (C-7), 126.1 ,124.6 (C-3), 123.1 (C-6), 110.4 (C-1), $62.4\left(\mathrm{CH}_{2}\right), 54.0$ (C-2'), 25.9 (C3'), 24.1 (C-4'). HRMS-ESI calculated for $\mathrm{C}_{16} \mathrm{H}_{20} \mathrm{NO}(\mathrm{M}+\mathrm{H})^{+} 242.15449$, found 242.15435 .

Step 3: 1-(Phenyldiazenyl)-3-(1-piperidinylmethyl)naphthalene-2-ol 3:

A solution containing of aniline $(0.28 \mathrm{~g}, 3.0 \mathrm{mmol})$ and concentrated $\mathrm{HCl}(3.0 \mathrm{ml})$ in distilled water $(50.0 \mathrm{ml})$ was stirred at $0-5^{\circ} \mathrm{C}$ for 45 minutes. To this solution a cold solution of sodium nitrite $(1.02 \mathrm{~g}, 14.5 \mathrm{mmol})$ in distilled water $(5.0 \mathrm{ml})$ was added slowly and the mixture was left stirring at $0-5^{\circ} \mathrm{C}$ for 45 minutes. The diazonium salt solution was added dropwise with vigorous stirring over 30 minutes to a solution of compound $\mathbf{C}(0.24 \mathrm{~g}, 1.0 \mathrm{mmol})$ in $0.2 \mathrm{M}$ aqueous sodium hydroxide $(10.0 \mathrm{ml})$ and THF $(10 \mathrm{ml})$ maintained at $0-5^{\circ} \mathrm{C}$. After completion of the addition the mixture was stirred in the cold for 45 minutes and subsequently 30 minutes at room temperature and the red-orange solid was filtered off. The filtrate was neutralized to pH 7 and extracted with dichloromethane $(3 \times 30 \mathrm{ml})$, then washed with water and finally dried over anhydrous sulphate and evaporated under reduced pressure. The solid residue was purified by flash column chromatography on silica gel, first with dichloromethane and then with dichloromethane/ethyl acetate (10:2) and finally with dichloromethane/methanol (95:5) to obtain the pure compound 3 as an orange solid $(0.22 \mathrm{~g}, 58 \%) .{ }^{1} \mathrm{H} \mathrm{NMR}\left(\mathrm{CDCl}_{3}, 500 \mathrm{MHz}\right)$ $\delta 16.64(\mathrm{~s}, \mathrm{OH}), 8.47$ (d, H-8, J= 8.2 Hz), 8.25 (broad s, H-4), 7.69 (d, H-5, J=7.6 Hz), 7.67 (dd, H-2',H-6' J=8.5 Hz, J=2.0 Hz), 7.55 (“t”, d H-7 $J=8.4 \mathrm{~Hz}$ and $J=1.2 \mathrm{~Hz}$ ), 7.48 (“t”, H$3^{\prime}$ and $\mathrm{H}-5, J=8.3 \mathrm{~Hz}$ ), 7.42 (t,d, H-6, $J=7.3 \mathrm{~Hz}$ and $\left.1.2 \mathrm{~Hz}\right) 7.31$ (t, H-4', $J=7.5 \mathrm{~Hz}$ ), 3.94 $\left(\mathrm{s}, \mathrm{CH}_{2}\right), 2.86$ (s, H-2',H-6'), 1.86 (s, H-3', H-5') and 1.26 (s, H-4'). For ${ }^{13} \mathrm{C}$ NMR data see Table 1. HRMS -ESI calculated for $\mathrm{C}_{22} \mathrm{H}_{24} \mathrm{~N}_{3} \mathrm{O}(\mathrm{M}+\mathrm{H})^{+} 346.19194$, found 346.19182. 


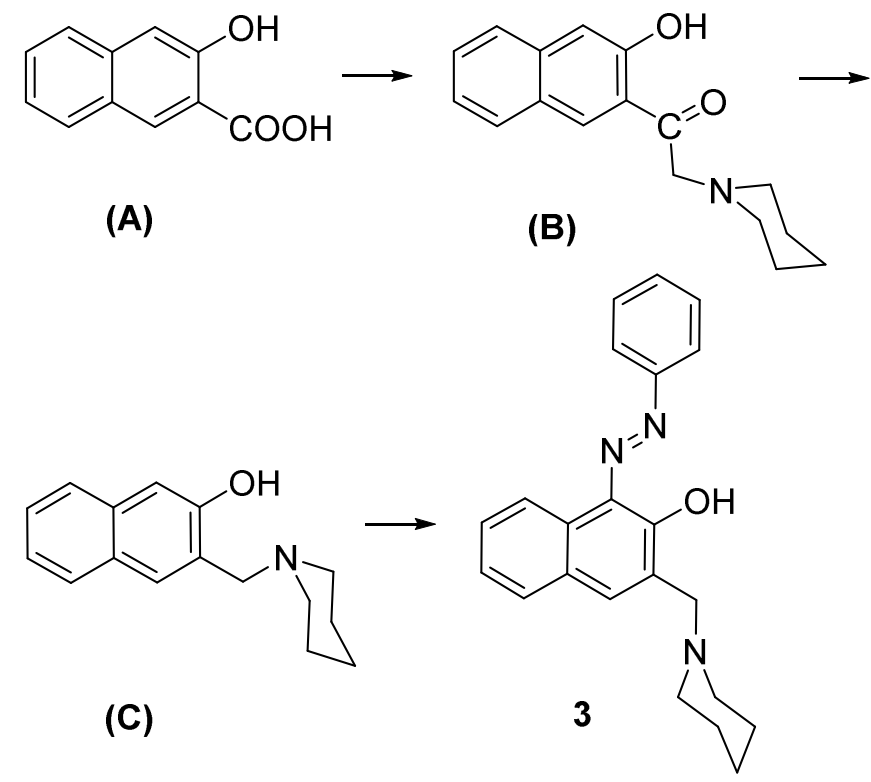

Scheme 4. Synthesis of compound 3.

\subsection{NMR measurements}

${ }^{1} \mathrm{H}$ NMR and ${ }^{13} \mathrm{C}$ NMR spectra were recorded either at $500 \mathrm{MHz}$ and $126 \mathrm{MHz}$ on a Bruker Ultrashield Plus 500 or $400 \mathrm{MHz}$ spectrometer using $\mathrm{CDCl}_{3}, \mathrm{CD}_{3} \mathrm{CN}$ or DMSO- $\mathrm{d}_{6}$ as a solvent and TMS as internal standard. The low temperature experiments were recorded in $\mathrm{CDCl}_{3}$. APT and $\mathrm{HMBC}$ (tuned to a $\mathrm{CH}$ coupling of $7 \mathrm{~Hz}$ ) spectra were recorded according to the Bruker standard procedures.

The assignments of the ${ }^{13} \mathrm{C}$ chemical shifts of $\mathbf{1}$ in $\mathrm{CDCl}_{3}$ are given in [9] based on carboncarbon coupling constants. The chemical shift changes in DMSO- $\mathrm{d}_{6}$ are minor (see Table 1) and as the changes mostly will be due to a change in the equilibrium, the variations are well documented for $\mathrm{C}-2$ and the benzene ring chemical shifts [11]. The assignments of the ${ }^{13} \mathrm{C}$ resonances of compound $\mathbf{2}$ are based on APT and HMBC spectra and on those of compound 1 combined with $\mathrm{OH}$ substituent effects and so are those of the titrated spectra. The assignment of the ${ }^{13} \mathrm{C}$ NMR spectrum of 2 in $\mathrm{CD}_{3} \mathrm{CN}$ was done by extrapolations as explained above. The assignment of $\mathbf{3}$ is partially based on APT and HMBC spectra. However, the assignment is complicated by the broadening of some lines and of one or two missing resonances in the aromatic region. These missing resonances are likely appearing at $223 \mathrm{~K}$. The ${ }^{1} \mathrm{H}$ spectrum is showing a broad H-4 resonance and C-4 is likewise broad at ambient temperature. C-2' and C-3' can be assigned based on intensities and confirmed together with $\mathrm{C}^{\prime} 4^{\prime}$ from the HMBC spectrum. C-1'and C-2 can be assigned based on chemical shifts. C-6 and C-8 can be assigned from the HMBC spectrum and C-4a and C-8a are identified from the APT spectrum 
and distinguished based on chemical shift arguments and supported by a $\mathrm{H}-7$ to carbon cross peak to $\mathrm{C}-8 \mathrm{a}$ in the $\mathrm{HMBC}$ spectrum.

\subsection{UV-Vis measurements}

Spectral measurements were performed on a Jasco V-570 UV-Vis-NIR spectrophotometer, equipped with a thermostatic cell holder (using Huber MPC-K6 thermostat with $1{ }^{0} \mathrm{C}$ precision) in spectral grade solvents at $20{ }^{\circ} \mathrm{C}$. Protonation was made with $96 \%$ sulfuric acid. Deprotonation was made with $25 \% \mathrm{NH}_{3}$. The derivative spectra were calculated according to the "step-by-step filter" procedure [12].

\subsection{Quantum chemical calculations}

Quantum-chemical calculations were performed by using the Gaussian 09 D.01 program suite [13]. DFT and time-dependent (TD)-DFT [14,15] were used to explore the ground- and excited-state properties of each molecule. For all cases, the solvent effect was described by applying the polarizable continuum model (PCM) in its integral equation formalism variant (IEFPCM) [16]. For all calculations, an M06-2X-fitted hybrid meta-GGA functional [17] and the TZVP basis set [18] were used, keeping in mind that this level of theory was shown to provide very good results in predicting tautomerism of azonaphthols [19]. All tautomeric forms of the investigated compounds were optimized without restrictions and then were characterized as true minima using vibrational frequency calculations.

The NMR calculations were done using the GIAO approximation [20] and B3LYP/6-31G(d) functional and basis set.

\subsection{Single crystal x-ray diffraction}

Single red block-shaped crystals of $\mathbf{3}$ were recrystallized from methanol by slow evaporation. A suitable crystal $(0.20 \times 0.15 \times 0.08) \mathrm{mm}^{3}$ was selected and mounted on a MiTeGen holder in oil on a STOE IPDS 2 diffractometer. The crystal was kept at $T=250 \mathrm{~K}$ during data collection. Using Olex2 [21], the structure was solved with the ShelXT [22] structure solution program, using the Intrinsic Phasing solution method. The model was refined with version 2017/1 of ShelXL [23] using Least Squares minimization.

Crystal Data. $\mathrm{C}_{22} \mathrm{H}_{23} \mathrm{~N}_{3} \mathrm{O}, M_{r}=345.43$, triclinic, $P-1$ (No. 2), $\mathrm{a}=10.8103(10) \AA, \mathrm{b}=$ 11.2369(12) А, $\mathrm{c}=17.1688(18) \AA, \alpha=80.314(10)^{\circ}, \beta=75.096(7)^{\circ}, \gamma=64.142(7)^{\circ}, V=$ 1809.8(3) $\AA^{3}, T=250 \mathrm{~K}, Z=4, Z^{\prime}=2, m\left(\mathrm{MoK}_{a}\right)=0.079,23416$ reflections measured, 6462 
unique $\left(R_{\text {int }}=0.1037\right)$ which were used in all calculations. The final $w R_{2}$ was 0.1013 (all data) and $R_{l}$ was $0.0426(\mathrm{I}>2(\mathrm{I}))$.

The single crystal data of $\mathbf{3}$ has been deposited at the Cambridge Crystallographic Data Centre and allocated the deposition number CCDC-1587825.

\section{Results and Discussion:}

\section{In solution:}

The absorption spectra of compounds 1-3, shown on Figure 1, clearly show the presence of the tautomeric mixture in solution, irrespective of the solvent used, with absorption maxima of the enol form in the range $410-430 \mathrm{~nm}$ and red shifted keto form absorbance around 500 nm. Detailed information can be found in the second derivative spectra. On Figure 2, the maximum of the enol form can be seen at $420 \mathrm{~nm}$ for $\mathbf{1}, 430 \mathrm{~nm}$ for $\mathbf{2}$ and $420 \mathrm{~nm}$ for $\mathbf{3}$. According to the derivative spectra, the keto form absorbance consists of several sub bands as shown previously from curve decomposition [8]. As seen from Figure 1a, compound 1 exists as tautomeric mixture in acetonitrile and DMSO with predominance towards the keto tautomer in chloroform, which can be expected because of the proton donor nature of the solvent [24].

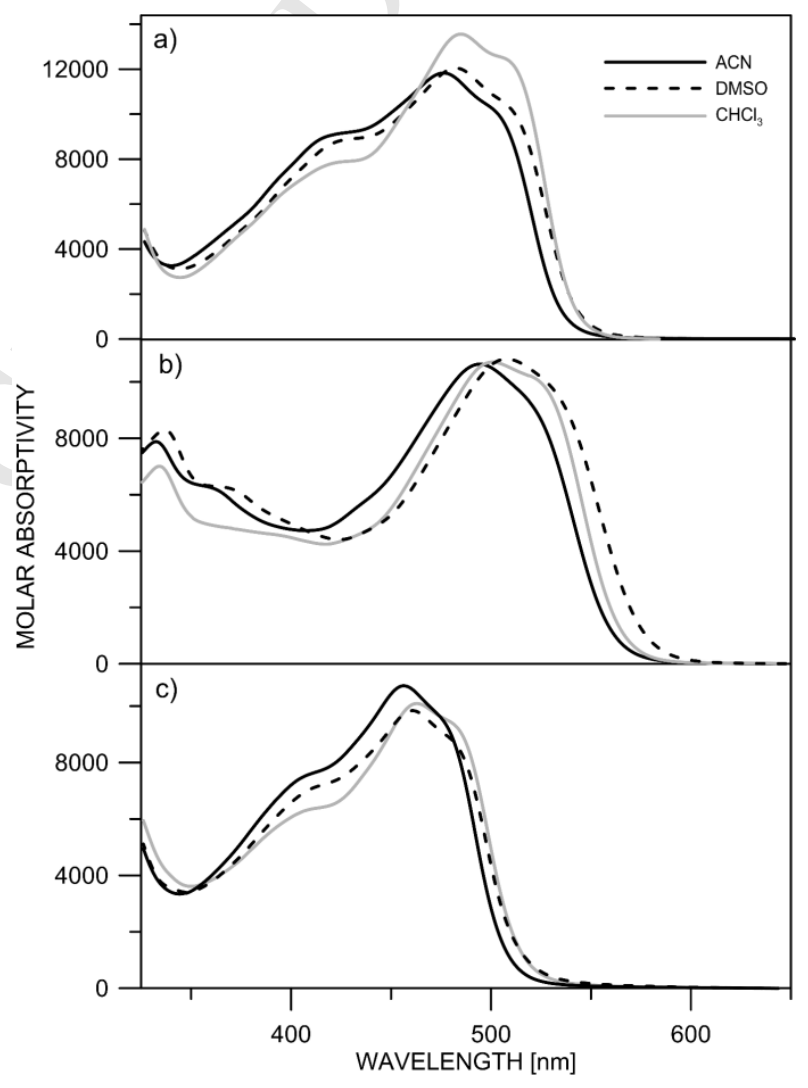


Figure 1. Absorption spectra of a) 1, b) $\mathbf{2}$ and c) $\mathbf{3}$ in various solvents.

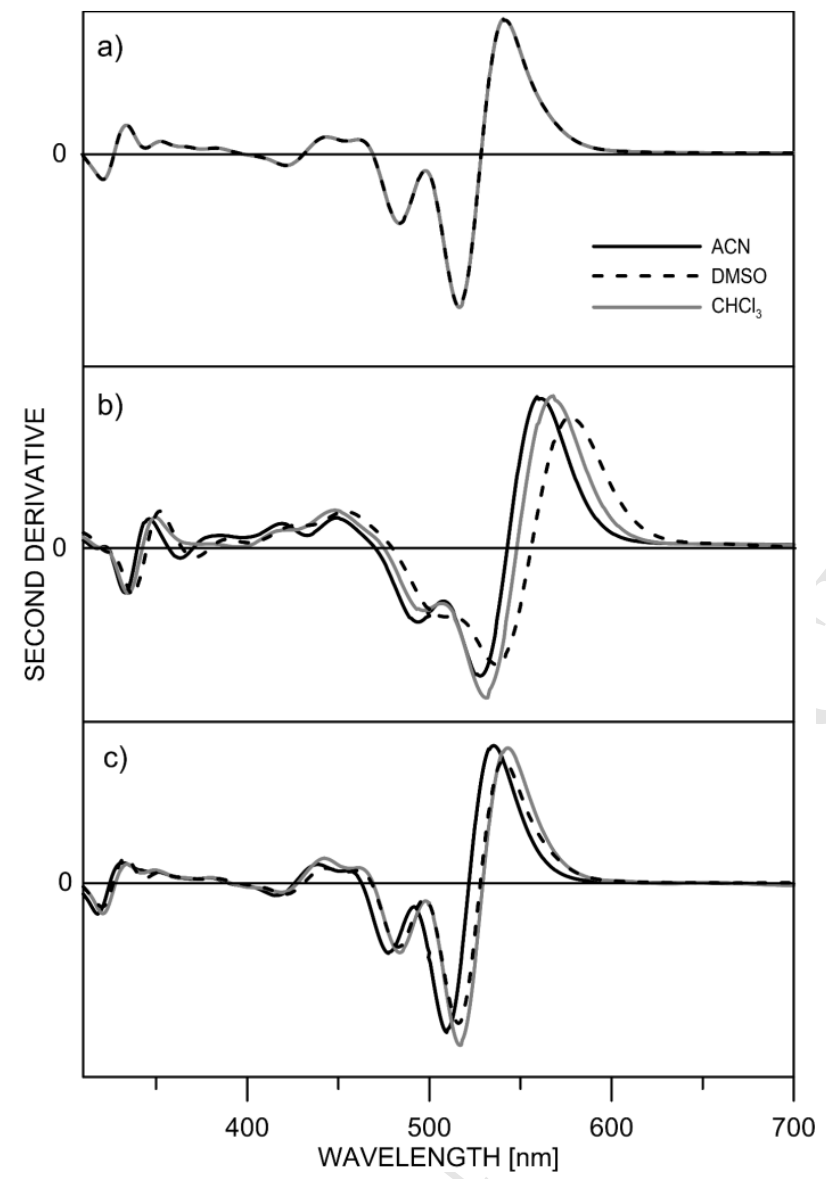

Figure 2. Second derivative spectra of a) 1, b) 2 and c) $\mathbf{3}$ in various solvents.

This conclusion is supported by the NMR results, taking into account the discussion in [25] about comparability of the UV-Vis and NMR data in tautomeric dyes. For $\mathbf{1}$ in $\mathrm{CDCl}_{3}$ a 70:30 ratio 1b:1a was found [11]. As seen from Table 1 both C-1'and C-4'are shifted towards higher frequency in DMSO- $\mathrm{d}_{6}$ which means a shift towards the enol form.

In the case of $\mathbf{2}$, the quantity of the enol form decreases from acetonitrile to chloroform and DMSO. According to the NMR a comparison with the calculated nuclear shielding (Table 2) gives that the hydrazo form is about $90 \%$ in DMSO.

Table 2. Calculated ${ }^{13} \mathrm{C}$ nuclear shielding for both tautomers of $\mathbf{2}$ as well as of the anions.

\begin{tabular}{|l|c|c|c|c|c|}
\hline $\begin{array}{l}\text { Carbons/ } \\
\text { tautomer }\end{array}$ & $\mathbf{2 a}$ & $\mathbf{2 a}^{-}$ & $\mathbf{2 b}$ & $\mathbf{2 b}^{-}$ & $\mathbf{2}^{-}$ \\
\hline C-1 & $64.2(63.8)^{\mathrm{a}}$ & 60.1 & $64.0(63.5)$ & 59.5 & 59.9 \\
\hline C-2 & $43.3(43.9)$ & 46.0 & $18.2(18.0)$ & 13.1 & 32.4 \\
\hline C-3 & $74.8(76.3)$ & 84.0 & $66.7(68.0)$ & 74.3 & 59.7 \\
\hline
\end{tabular}




\begin{tabular}{|l|l|l|l|l|l|}
\hline C-4 & $59.3(59.8)$ & 53.7 & $54.2(53.8)$ & 44.4 & 67.5 \\
\hline C-4a & $66.7(66.9)$ & 62.7 & $66.0(61.6)$ & 65.8 & 70.6 \\
\hline C-5 & $83.9(84.8)$ & 80.8 & $81.3(81.6)$ & 72.8 & 86.5 \\
\hline C-6 & $44.7(41.9)$ & 27.6 & $43.4(41.1)$ & 23.9 & 50.6 \\
\hline C-7 & $78.8(75.3)$ & 60.2 & $80.3(77.6)$ & 68.9 & 85.4 \\
\hline C-8 & $71.7(71.7)$ & 75.3 & $71.7(71.4)$ & 70.3 & 73.5 \\
\hline C-8a & $67.5(68.1)$ & 81.8 & $67.7(68.8)$ & 87.0 & 60.4 \\
\hline C-1' & $46.0(45.8)$ & 43.7 & $54.9(54.6)$ & 52.2 & 37.2 \\
\hline C-2' & $66.1(66.4)$ & 71.0 & $78.7(79.1)$ & 83.9 & 67.9 \\
\hline C-6' & $81.4(81.3)$ & 81.2 & $81.8(81.3)$ & 83.8 & 84.5 \\
\hline C-3' & $67.3(67.5)$ & 69.7 & $67.3(67.5)$ & 69.9 & 70.3 \\
\hline C-5' $^{\prime}$ & $67.4(67.5)$ & 66.5 & $66.5(66.6)$ & 67.8 & 70.5 \\
\hline C-4’ $^{\prime}$ & $66.8(67.3)$ & 75.2 & $71.8(72.6)$ & 81.9 & 78.8 \\
\hline
\end{tabular}

a Values in brackets are for a molecule with a DMSO molecule hydrogen bonded to the nontautomeric $\mathrm{OH}$ hydrogen.

The absorption spectra of $\mathbf{3}$ are similar as shape of the curve and position of the absorption maxima as those in $\mathbf{1}$, proving that the sidearm chain does not influence the position of the tautomeric equilibrium.

The presence of the tautomeric mixture in $\mathbf{2}$ and $\mathbf{3}$, can be confirmed by a simple experiment. It is well known that the addition of water shifts the tautomeric equilibrium towards the keto form in azonaphthols $[25,26]$. As shown on Figure 3, in both compounds, the addition of water leads to a decrease of the maximum of the enol form and correspondingly increase of the band belonging to the keto tautomer. If only the keto form is presented in solution, no spectral shifts could be observed. 


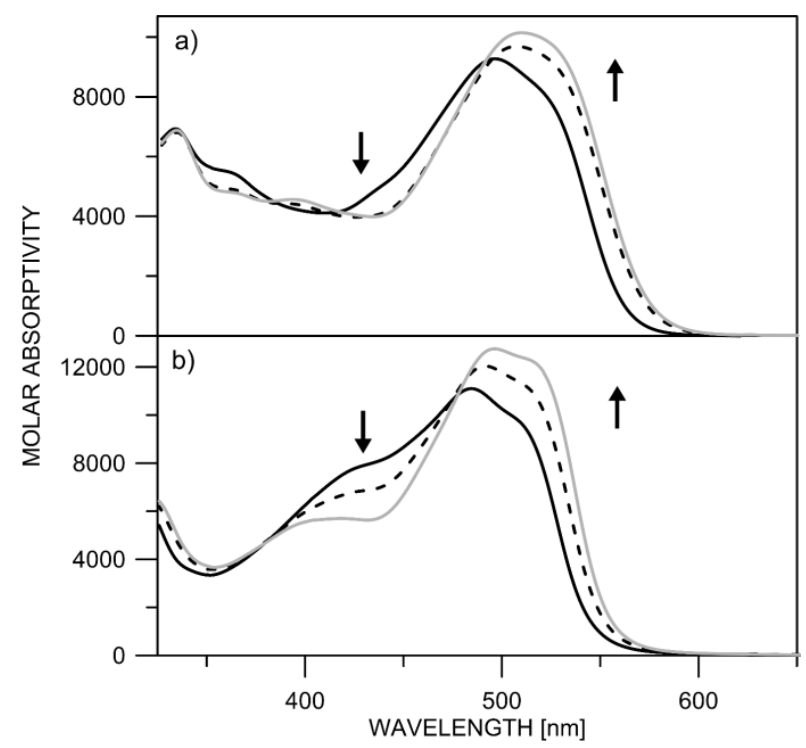

Figure 3. Absorption spectra of a) $\mathbf{2}$ and b) $\mathbf{3}$ in ACN and DMSO, upon water addition: (without water addition; — final spectrum upon water addition).
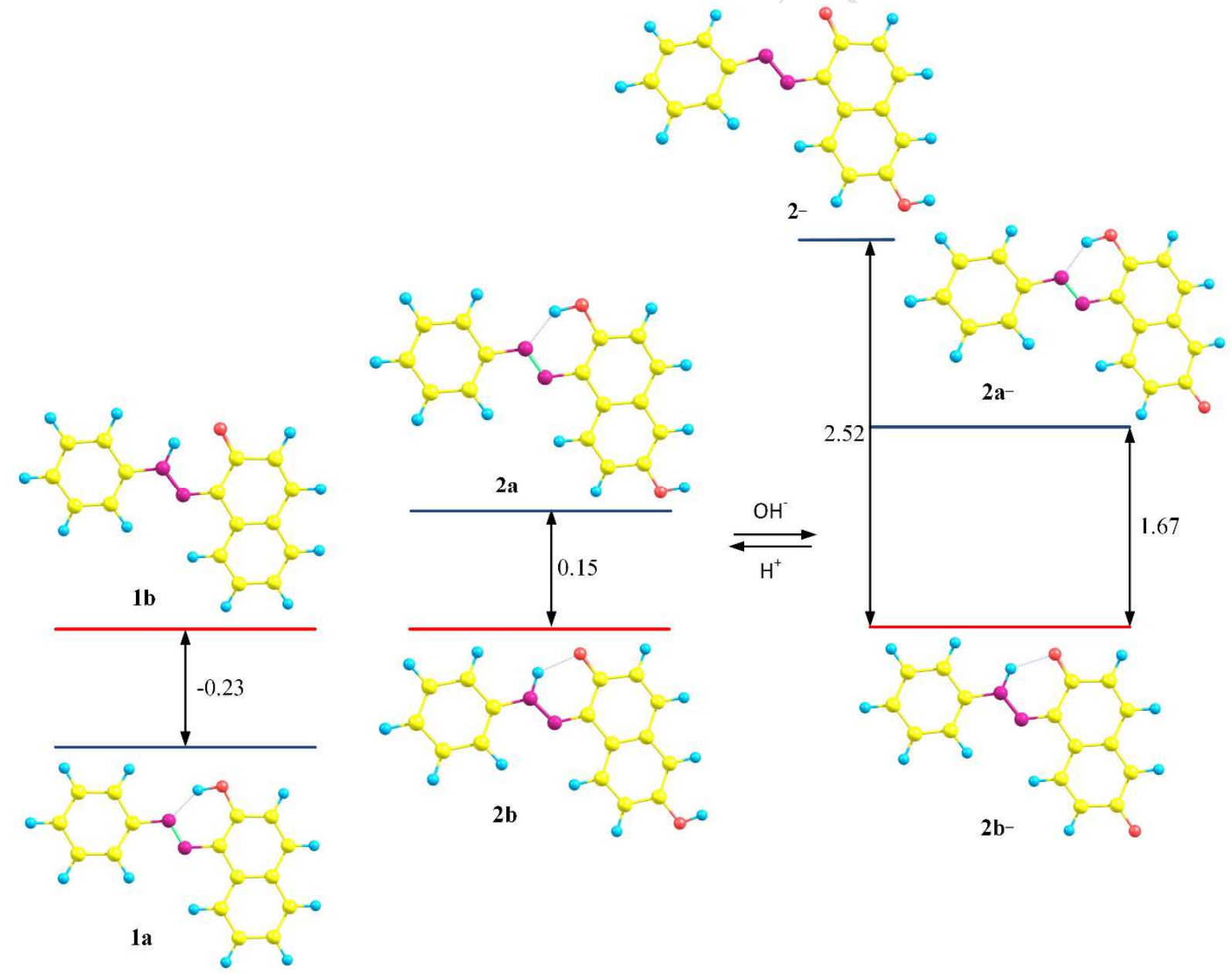

Figure 4. Relative energies (M06-2X/TZVP, in kcal/mol) of the tautomers of $\mathbf{1}$ in ACN (left). Relative energies (M06-2X/TZVP, in $\mathrm{kcal} / \mathrm{mol}$ ) of the neutral tautomers (center) and deprotonated forms of 2 in ACN (right). 
The coexistence of the tautomers in the studied compounds is confirmed by the theoretical calculations as well. The moderate energy gap between the enol and the keto tautomeric forms, suggests that compound $\mathbf{1}$ always exists as a tautomeric mixture (1a and $\mathbf{1 b}$, Figure 4, left) in solution as it is actually observed [8]. The implementation of an additional nontautomeric hydroxyl group (compound 2) does not change the situation dramatically. Actually, it acts as a simple electron acceptor substituent shifting the tautomeric equilibrium towards the keto form $\mathbf{2 b}$ (Figure 4, centre). Compound $\mathbf{2}$ has two options for deprotonation: loss of the tautomeric proton giving non-tautomeric anion $\mathbf{2}^{-}$or deprotonation of the additional $\mathrm{OH}$ group, which could affect the tautomeric equilibrium ( $\mathbf{2 a}^{-}$vs $\mathbf{2} \mathbf{b}^{-}$, Figure 4 , right). As seen from the calculations, the anion $\mathbf{2}^{-}$is energetically unfavourable, which means that the deprotonation occurs at the additional $\mathrm{OH}$ group. As a result, the tautomeric equilibrium between $\mathbf{2} \mathbf{a}^{-}$and $\mathbf{2} \mathbf{b}^{-}$is almost fully shifted to the keto tautomer $\mathbf{2} \mathbf{b}^{-}$with an energy gap of 1.67 $\mathrm{kcal} / \mathrm{mol}$.

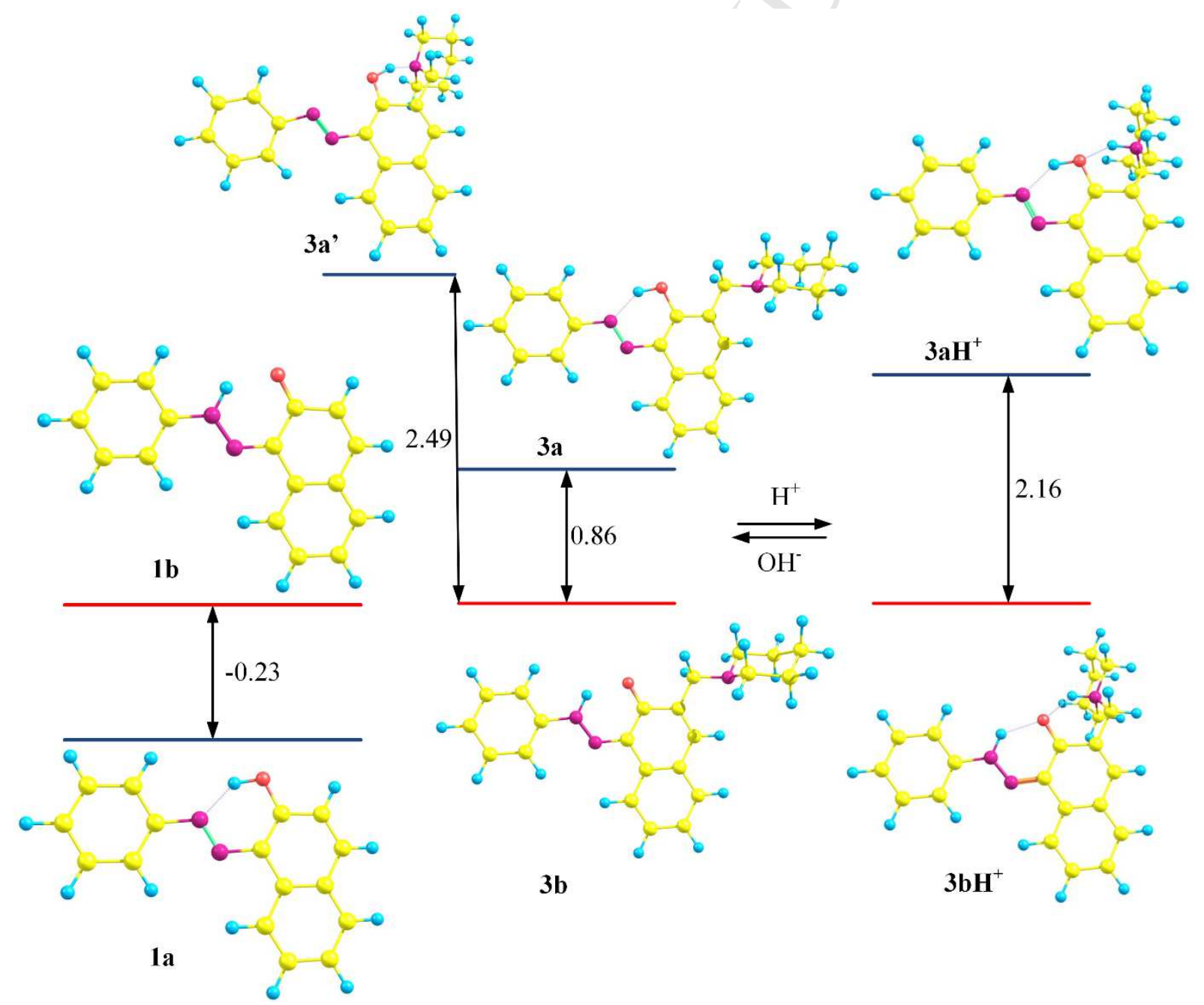

Figure 5. Relative energies (M06-2X/TZVP, in kcal/mol) of the neutral tautomers of 3 (left) and the protonated species in ACN (right). 
Compound $\mathbf{3}$ possesses an option for competitive hydrogen bonding in the enol form, where the tautomeric proton interacts either with the nitrogen from the azo group (3a, Scheme 2), or with the nitrogen atom from the piperidine unit (3a'). As seen from Figure 5 left, the structure 3a is preferred. Actually, there is no competition for the tautomeric proton, between the nitrogen atom from the chromophore backbone and the nitrogen atom from the piperidine unit (energy gap of $2.5 \mathrm{kcal} / \mathrm{mol}$ between $\mathbf{3 a}$ ' and $\mathbf{3 b}$ ). Although the overall effect of the existence of the sidearm stabilizes the keto tautomer $\mathbf{3 b}$ (in comparison with $\mathbf{1}$ ), a substantial amount of 3a could be expected in solution as the energy gap of $0.86 \mathrm{kcal} / \mathrm{mol}$ suggests. Obviously, the sidearm acts as a simple alkyl substituent, because when the whole sidearm is replaced by a methyl group the energy gap between tautomers 3a and $\mathbf{3 b}$ remains almost the same - 0.7 $\mathrm{kcal} / \mathrm{mol}$.

The X-ray analysis of compound $\mathbf{3}$, as will be shown below, clearly shows that compound $\mathbf{3}$ exists as the keto form $\mathbf{3 b}$ in the solid state and the nitrogen atom from the piperidine unit is far from the tautomeric backbone, as predicted by the theoretical calculations (Figure 5). The NMR data show at room temperature very broad $\mathrm{H}-4$ and $\mathrm{C}-4$ resonances and one missing C3 resonance. It was found in [27] that the piperidine ring was flipping at ambient temperature and that the flipping could be stopped by lowering the temperature. Upon cooling the $\mathrm{H}-4$ and C-4 resonances broaden even further, whereas those of H-2", H-6" and H-4" each split into two indicating that the ring flipping has slowed down, whereas the corresponding ${ }^{13} \mathrm{C}$ resonances do not split either indicating that the piperidine ring is positioned symmetrically with respect to the naphthalene ring or the piperidine ring is moving with respect to the piperidine ring. However, the broadening of the resonances at ambient temperature can only be explained if the piperidine ring is pointing in the direction of $\mathrm{H}-4$ as shown in Scheme 2. This means that the hydrogen bond is clearly between the substituents at C-1 and C-2 as also indicated by the very high frequency shift of the $\mathrm{XH}$ proton ( $\mathrm{XH}$ means either $\mathrm{OH}$ or $\mathrm{NH}$ ).

As seen from Figure 5 right, the acid addition is a suitable stimulus for switching the tautomeric equilibrium to the pure keto form, because the protonated piperidine nitrogen atom, participates in additional intramolecular hydrogen bond formation, which further stabilizes the keto form, shifting the equilibrium fully towards the keto form.

The calculated positions of the absorption maxima of the corresponding enol and keto forms of the neutral compounds collected in Table 1 logically follow the spectral changes in solution. The calculated absorption maxima of the enol and keto forms respectively in compounds $\mathbf{1}$ and $\mathbf{3}$, coincide, as observed by the experiment. In case of $\mathbf{2}$, the calculated absorption maximum of the enol form is slightly red shifted, compared to $\mathbf{1}$ and $\mathbf{3}$, and the 
position of the keto form absorbance is not affected. As seen from Table 3, the deprotonation of 2 leads to red shift in the maxima of both enol and keto tautomers, while the protonation of 3 does not bring substantial effect, which is logical having in mind that the protonated nitrogen atom from the piperidine unit is not conjugated to the chromophore system.

As seen from Figure S1, in which deprotonation of $\mathbf{1}$ and $\mathbf{2}$ is compared, the addition of base to the solution of $\mathbf{2}$, leads to decrease of the maximum of the keto form at $500 \mathrm{~nm}$ and appearance of a new band at $600 \mathrm{~nm}$. This additional band, which is not observed in $\mathbf{1}$, gives indication that in $\mathbf{2}$, the additional hydroxyl group is deprotonated as theoretical calculations suggest.

Addition of one equivalent of tetrabutylammonium hydroxide to $\mathbf{2}$ led to precipitation so the NMR results shown in Scheme 5 are for addition of 0.66 equivalent of base. High frequency shifts are found for C-2, C-5, C-6, C-7 and C-1', whereas C-3 and C-8a are shifted to low frequency. The interpretation may be complicated by the fact that two tautomers exist and the equilibrium constant may change as a function of titration. Titration of the phenol group of 3hydroxybenzoic acid led to a high frequency shift for C-3 whereas that of C-6 was shifted to high frequency [28]. As discussed above, in case of 2 titration may occur either at O-2 or at the nitrogen depending on the tautomeric form $\left(\mathbf{2}^{-}\right)$or at O-6 (2a- $\left./ \mathbf{2} \mathbf{b}^{-}\right)$. Looking at the changes in ${ }^{13} \mathrm{C}$ chemical shifts of Scheme 5 the picture is not immediately clear. However, taking the calculated nuclear shieldings of Table 2 into account it is obvious that the $\mathrm{OH} / \mathrm{NH}$ proton at $\mathrm{C}-2$ or $\mathrm{N}$ is not titrating as this would lead to a considerable low frequency shifts of $\mathrm{C}-2$ (remember that the nuclear shieldings and the chemical shifts have opposite signs). The opposite is found. The change in chemical shifts around C-6 is in agreement with the finding for 3-hydroxybenzoic acid as mentioned above. Based on these findings the $\mathrm{OH}$ proton at C-6 is titrated in DMSO using tetrabutylammonium hydroxide as base. The high frequency shift of $\mathrm{C}-1$ 'can due both to titration and to a shift in the equilibrium. However, the low frequency of the C-4' could also be due to titration, but the small magnitude indicates that it is most likely both due to titration (low frequency shift) and a shift in the equilibrium versus the azoform (high frequency shift).

As seen from Figure 6, the addition of acid leads to gradual shift of the tautomeric equilibrium in 3 to the keto form, which can be monitored with the decreasing absorption maxima of the enol form and raise of the red shifted absorption of $\mathbf{3 b}$. As a result, the pure spectrum of the keto form can be seen, which approximates very well with the pure spectrum of $\mathbf{1 b}$ obtained by overlapping bands decomposition [8]. The process is reversible upon base addition, which shows that the tautomerism in $\mathbf{3}$ can be controlled. 


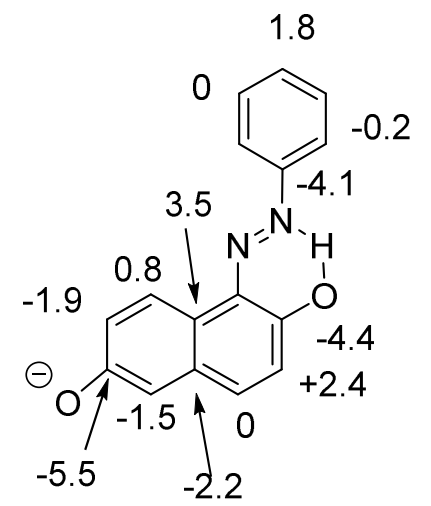

Scheme $5 .{ }^{13} \mathrm{C}$ titration shifts of 2 after addition of 0.66 equivalents of tetrabutylammonium hydroxide

Table 3. Predicted values for the neutral forms of $\mathbf{1}-\mathbf{3}$ and ionized forms of $\mathbf{2}$ and $\mathbf{3}$ (see Figures 1 and 2).

\begin{tabular}{|c|c|c|c|c|}
\hline \multicolumn{3}{|c|}{ neutral forms } & \multicolumn{2}{c|}{ ionized forms } \\
\hline \multirow{2}{*}{ compound } & $\begin{array}{c}\lambda_{\max }, \mathrm{f}^{*} \\
\text { enol }\end{array}$ & $\begin{array}{c}\lambda_{\max }, \mathrm{f} \\
\text { keto }\end{array}$ & $\begin{array}{c}\lambda_{\max }, \mathrm{f} \\
\text { enol }\end{array}$ & $\begin{array}{c}\lambda_{\max }, \mathrm{f} \\
\text { keto }\end{array}$ \\
\hline $\mathbf{1}$ & $374 ; 0.63$ & $405 ; 0.61$ & - & - \\
\hline $\mathbf{2}$ & $390 ; 0.51$ & $405 ; 0.61$ & $537 ; 0.13$ & $569 ; 0.28$ \\
\hline $\mathbf{3}$ & $376 ; 0.64$ & $404 ; 0.62$ & $372 ; 0.63$ & $418 ; 0.63$ \\
\hline
\end{tabular}

*f - oscillator strength

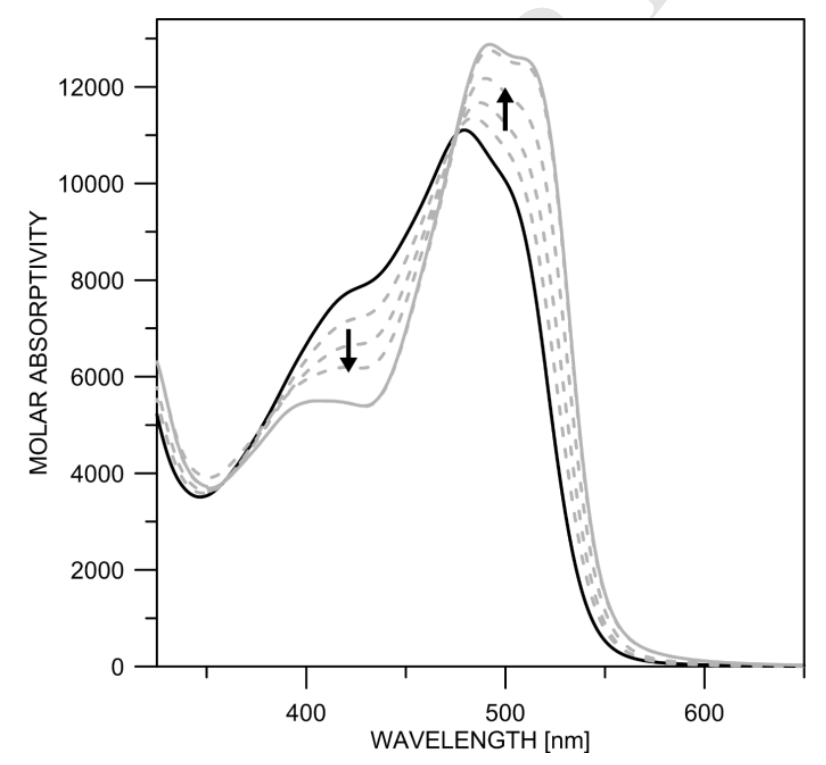

Figure 6. Absorption spectra of $\mathbf{3}$ in ACN upon acid addition: (- without acid addition; final spectrum upon acid addition). 


\section{In the solid state:}

The X-ray analysis of compound $\mathbf{3}$, presented on Figure 7, clearly shows that compound $\mathbf{3}$ exists as a keto form $\mathbf{3 b}$ in the solid state and that the nitrogen atom from the piperidine unit is far from the tautomeric backbone, as predicted by the theoretical calculations (Figure 5). Compound 3 crystallizes in the space group $P-1$ (No. 2) with two independent molecules A and B per asymmetric unit. Molecule A, around O1, features an angle of $16.2^{\circ}$ between the mean angle comprising the phenyl ring, and the one of the naphthyl ring. Furthermore, the $\mathrm{C} 8-\mathrm{O} 1$ bond is 1.276(4) $\AA$ long, and in the adjacent aromatic ring, the $\mathrm{C}-\mathrm{C}$ distances are distributed alternatingly as follows: C8-C9 1.448(5), C9-C10 1.325(5), C10-C11 1.466(6), C11-C16 1.397(5), C16-C7 1.462(4) and C7-C8 1.426(6) A. The distances C7-N2 and N2$\mathrm{N} 1$ are respectively $1.337(5)$ and 1.328(4) $\AA$ long, indicating the trend of distances expected from the structure of $\mathbf{3 b}$, except for the fact that the N1-N2 bond seems shorter than the expected $\mathrm{N}-\mathrm{N}$ single bond of 1.47 , but longer than a $\mathrm{N}=\mathrm{N}$ bond with $1.24 \AA$ (see Figure $\mathrm{S} 2$ and S3). The N1...O1 distance is 2.523(5) $\AA$, the distance $\mathrm{H} 1 \ldots \mathrm{O} 1$ is $1.748 \AA$, and a stable 6ring is thus stabilized in molecule A via $\mathrm{N} 1-\mathrm{H} 1-\mathrm{O} 1$ of $133.9^{\circ}$. O1 makes a short contact of $2.510 \AA$ to $\mathrm{H} 18 \mathrm{~B}$ of a neighbor molecule $\mathrm{A}^{\prime}(3-\mathrm{x},-\mathrm{y},-1-\mathrm{z})$, which is another confirmation of the fact that the molecule $\mathrm{A}$ is in its keto form.

In molecule B, the phenyl and naphthyl groups form an angle of only $13.3^{\circ}$ to each other, and the O2-C30 distance is even shorter than in molecule A, with 1.269(5) $\AA$. The distances in the aromatic ring bearing $\mathrm{O} 2$ are $\mathrm{C} 30-\mathrm{C} 31$ 1.451(4), C31-C32 1.350(5), C32-C33 1.437(5), C33-C38 1.407(4), C38-C29 1.440(5) and C29-C30 1.453(6) A, while the distances C29-N5 and N5-N4 are respectively 1.334(4) and 1.310(5) A long. The N4...O2 distance is $2.501 \AA$ and H4A is $1.754 \AA$ away from the $\mathrm{O} 2$. This H-bond is again stabilized by a stable 6-ring with an $\mathrm{N}-\mathrm{H}-\mathrm{O}$ angle of $137.8^{\circ}$. O2 also makes a short contact to H44B of another molecule B' (2-x, -2-y, -z) at $2.449 \AA$, which is even shorter than for molecule A and A'. Yet, the N-N distance in molecule $\mathrm{B}$ is significantly shorter than in $\mathrm{A}$, which might indicate a more stable azo-group. Nevertheless, in both molecules A and B, the $\mathrm{H}$-atom involved in tautomerism (H1 or H4A) is completely found linked to the respective nitrogen atom, with the $\mathbf{3 b}$ form as clearly the most stable one. The crystal structure further supports the discussion on the piperidyl entity, which is turned away from the tautomeric site. Indeed, in molecule A, a short contact between the N3 atom and H10 is found to be $2.505 \AA$ long (N3-C10 2.872(2) $\AA$ ), while in molecule $\mathrm{B}$, the analogue distance between N6 and $\mathrm{H} 32$ is $2.580 \AA$ (N6-C32 
2.923(2) $\AA$ ). Both N-atoms, N3 and N6, are also fixed in their pyramidal conformation with angle sums of ca. $328.6 \pm 0.7^{\circ}$ on average.

The partially significant differences between molecules A and B might as well occur from packing effects. Indeed, there are offset parallel $\pi$ - $\pi$ interactions as well as $\mathrm{C}-\mathrm{H} \ldots \pi$ interactions as follows: $\mathrm{H} 25$ of a molecule B undergoes $\mathrm{C}-\mathrm{H} \ldots \pi$ interactions with $\mathrm{C} 2$ and $\mathrm{C} 3$ of molecule $\mathrm{A}$ at distances of respectively 2.878 and $2.837 \AA$, with an angle between the two involved phenyl groups of almost $72^{\circ}$. Further packing involves a pair of two offset molecules B, arranged head-to-tail which interact twice via C30 of one and C24 of the neighbor molecule (and vice versa) at a distance of 3.368(6) $\AA$. The molecules of A are also packed in an antiparallel way with an offset parallel packing of the naphthyl groups, but the average distances between the aromatic cores is typically longer than $3.55 \AA$, so only weak interactions can be considered. Stacks of A and stacks of B lead to a chevron type arrangement in the three dimensional packing.

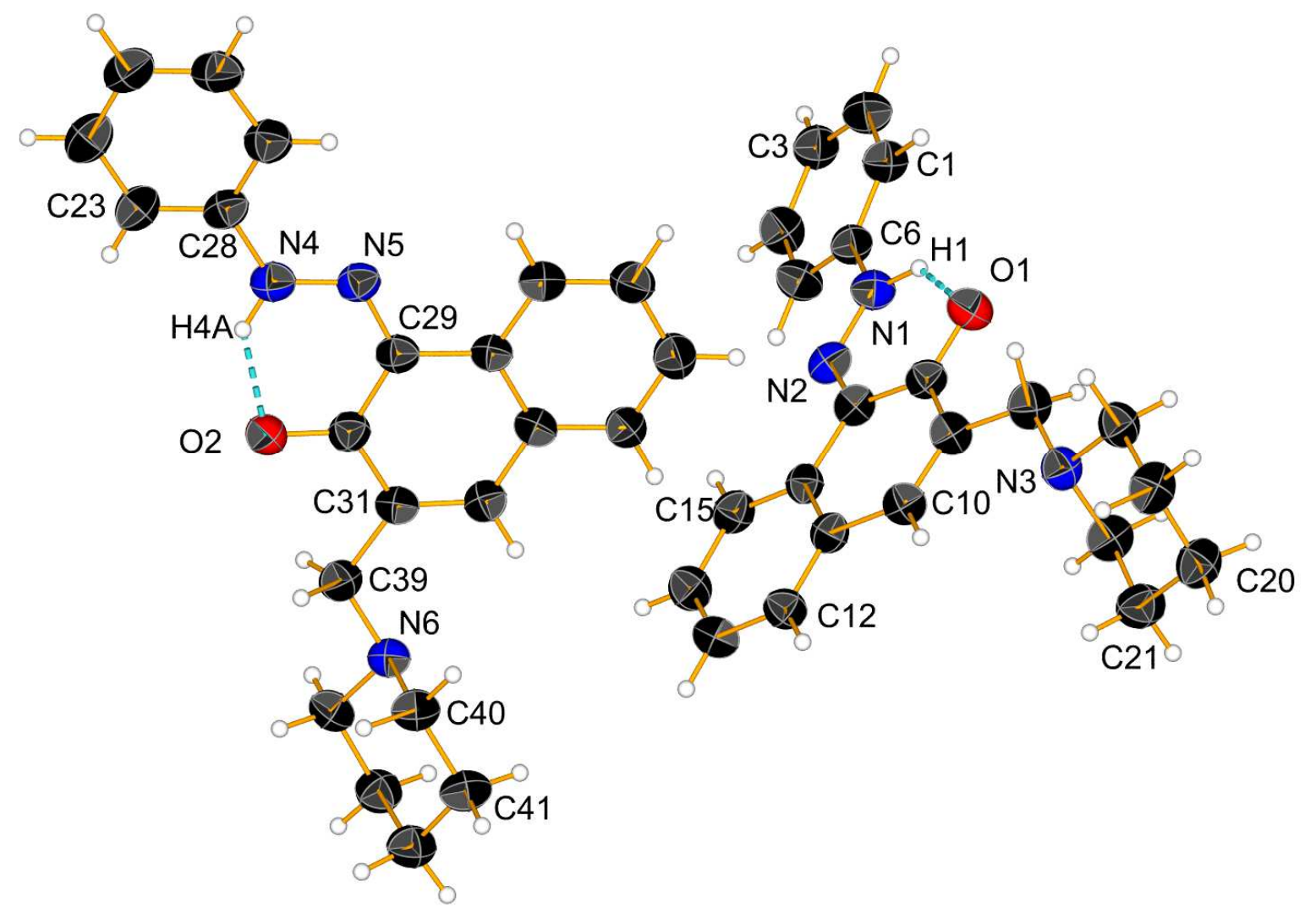

Figure 7. X-ray analysis of $\mathbf{3}$, ellipsoids are represented with $30 \%$ of probability, $\mathrm{H}$ bonds are drawn as blue dashed lines. 


\section{Conclusions:}

Compounds 1, $\mathbf{2}$ and $\mathbf{3}$ exist as tautomeric mixtures in solution as shown by UV-VIS, NMR spectroscopy and quantum chemical calculations. The structural changes in $\mathbf{2}$ and $\mathbf{3}$, make possible to control the tautomerism in solution.

In the case of $\mathbf{2}$, a shift in the equilibrium can be achieved through deprotonation of the additional hydroxyl group, while in $\mathbf{3}$, the protonation of the piperidine nitrogen stimulates shift to the keto tautomer.

Compound $\mathbf{3}$ is more suitable as tautomeric switch, because the piperidine unit is not conjugated to the tautomeric backbone and the protonation process does not influence the absorption spectra directly.

\section{Acknowledgements:}

The financial support by the Swiss National Science Foundation (SupraMedChem@Balkans.Net SCOPES Institutional Partnership) and Bulgarian Science Fund (Bulgarian Science Fund and DAAD joint research project DNTS01/04 Proton Cranes) is gratefully acknowledged. In addition, we acknowledge the access to computational facilities provided by Project MADARA (Project RNF01/0110). 


\section{References:}

[1] Zollinger H. Color chemistry: syntheses, properties, and applications of organic dyes and pigments. 3rd, ed ed. Zürich : Weinheim: Verlag Helvetica Chimica Acta ; Wiley-VCH; 2003.

[2] Nedeltcheva-Antonova D, Antonov L. Controlled Tautomerism: Is It Possible? In: Antonov L, editor. Tautomerism, Weinheim, Germany: Wiley-VCH Verlag GmbH \& Co. KGaA; 2016, p. 273-94. doi:10.1002/9783527695713.ch12.

[3] Antonov LM, Kurteva VB, Simeonov SP, Deneva VV, Crochet A, Fromm KM. Tautocrowns: a concept for a sensing molecule with an active side-arm. Tetrahedron 2010;66:4292-7. doi:10.1016/j.tet.2010.04.049.

[4] Antonov L, Deneva V, Simeonov S, Kurteva V, Nedeltcheva D, Wirz J. Exploiting Tautomerism for Switching and Signaling. Angew Chem Int Ed 2009;48:7875-8. doi:10.1002/anie.200903301.

[5] Ball P, Nicholls CH. Azo-hydrazone tautomerism of hydroxyazo compounds-a review. Dyes Pigments 1982;3:5-26. doi:10.1016/0143-7208(82)80010-7.

[6] Kelemen J. Azo-hydrazone tautomerism in azo dyes. III. The tautomeric structure of 1(4'-nitrophenylazo)-2-naphthylamine from crystal structure determination. Dyes Pigments 1982;3:249-71. doi:10.1016/0143-7208(82)80001-6.

[7] Lyčka A, Hansen PE. Deuterium isotope effects on $13 \mathrm{C}$ and15N nuclear shielding inohydroxyazo dyes. Org Magn Reson 1984;22:569-72. doi:10.1002/mrc.1270220910.

[8] Antonov L, Stoyanov S, Stoyanova T. Tautomeric equilibrium in 1-phenylazo-2naphthol—A quantitative study. Dyes Pigments 1995;27:133-42. doi:10.1016/01437208(94)00042-Z.

[9] Hansen PE, Lyčka A. Carbon-carbon coupling constants of 1-phenylazo-2-naphthol and 2-phenylazo-1-naphthol obtained by the SEMINA-1 technique. Magn Reson Chem 1986;24:772-6. doi:10.1002/mrc.1260240908.

[10] Li X, Hewgley JB, Mulrooney CA, Yang J, Kozlowski MC. Enantioselective Oxidative Biaryl Coupling Reactions Catalyzed by 1,5-Diazadecalin Metal Complexes: Efficient Formation of Chiral Functionalized BINOL Derivatives. J Org Chem 2003;68:5500-11. doi:10.1021/jo0340206.

[11] Lyčka A, Šnobl D, Macháček V, Večeřa M. 13C NMR spectra of non-labelled and15N-mono-labelled azo dyes. Org Magn Reson 1981;15:390-3. doi:10.1002/mrc.1270150413.

[12] Antonov L. Drawbacks of the present standards for processing absorption spectra recorded linearly as a function of wavelength. TrAC Trends Anal Chem 1997;16:536-43. doi:10.1016/S0165-9936(97)00064-2.

[13] Gaussian 09, Revision D.01, M. J. Frisch, G. W. Trucks, H. B. Schlegel, G. E. Scuseria, M. A. Robb, J. R. Cheeseman, G. Scalmani, V. Barone, G. A. Petersson, H. Nakatsuji, X. Li, M. Caricato, A. Marenich, J. Bloino, B. G. Janesko, R. Gomperts, B. Mennucci, H. P. Hratchian, J. V. Ortiz, A. F. Izmaylov, J. L. Sonnenberg, D. WilliamsYoung, F. Ding, F. Lipparini, F. Egidi, J. Goings, B. Peng, A. Petrone, T. Henderson, D. Ranasinghe, V. G. Zakrzewski, J. Gao, N. Rega, G. Zheng, W. Liang, M. Hada, M. Ehara, K. Toyota, R. Fukuda, J. Hasegawa, M. Ishida, T. Nakajima, Y. Honda, O. Kitao, H. Nakai, T. Vreven, K. Throssell, J. A. Montgomery, Jr., J. E. Peralta, F. Ogliaro, M. Bearpark, J. J. Heyd, E. Brothers, K. N. Kudin, V. N. Staroverov, T. Keith, R. Kobayashi, J. Normand, K. Raghavachari, A. Rendell, J. C. Burant, S. S. Iyengar, J. Tomasi, M. Cossi, J. M. Millam, M. Klene, C. Adamo, R. Cammi, J. W. Ochterski, R. L. Martin, K. Morokuma, O. Farkas, J. B. Foresman, and D. J. Fox, Gaussian, Inc., Wallingford CT, 2013. n.d. 
[14] Furche F, Ahlrichs R. Adiabatic time-dependent density functional methods for excited state properties. J Chem Phys 2002;117:7433-47. doi:10.1063/1.1508368.

[15] Casida ME, Jamorski C, Casida KC, Salahub DR. Molecular excitation energies to high-lying bound states from time-dependent density-functional response theory: Characterization and correction of the time-dependent local density approximation ionization threshold. J Chem Phys 1998;108:4439-49. doi:10.1063/1.475855.

[16] Tomasi J, Mennucci B, Cammi R. Quantum Mechanical Continuum Solvation Models. Chem Rev 2005;105:2999-3094. doi:10.1021/cr9904009.

[17] Zhao Y, Truhlar DG. Density Functionals with Broad Applicability in Chemistry. Acc Chem Res 2008;41:157-67. doi:10.1021/ar700111a.

[18] Weigend F. Accurate Coulomb-fitting basis sets for H to Rn. Phys Chem Chem Phys 2006;8:1057. doi:10.1039/b515623h.

[19] Kawauchi S, Antonov L. Description of the Tautomerism in Some Azonaphthols. J Phys Org Chem 2013;26:643-52. doi:10.1002/poc.3143.

[20] Wolinski K, Hinton JF, Pulay P. Efficient implementation of the gauge-independent atomic orbital method for NMR chemical shift calculations. J Am Chem Soc 1990;112:8251-60. doi:10.1021/ja00179a005.

[21] Dolomanov OV, Bourhis LJ, Gildea RJ, Howard JAK, Puschmann H. OLEX2 : a complete structure solution, refinement and analysis program. J Appl Crystallogr 2009;42:339-41. doi:10.1107/S0021889808042726.

[22] Sheldrick GM. SHELXT - Integrated space-group and crystal-structure determination. Acta Crystallogr Sect Found Adv 2015;71:3-8. doi:10.1107/S2053273314026370.

[23] Sheldrick GM. Crystal structure refinement with SHELXL. Acta Crystallogr Sect C Struct Chem 2015;71:3-8. doi:10.1107/S2053229614024218.

[24] Fabian WMF, Antonov L, Nedeltcheva D, Kamounah FS, Taylor PJ. Tautomerism in Hydroxynaphthaldehyde Anils and Azo Analogues: a Combined Experimental and Computational Study. J Phys Chem A 2004;108:7603-12. doi:10.1021/jp048035z.

[25] Nedeltcheva D, Antonov L, Lycka A, Damyanova B, Popov S. Chemometric Models For Quantitative Analysis of Tautomeric Schiff Bases and Azo Dyes. Curr Org Chem 2009;13:217-40. doi:10.2174/138527209787314832.

[26] Antonov L, Fabian WMF, Taylor PJ. Tautomerism in some aromatic Schiff bases and related azo compounds: an LSER study. J Phys Org Chem 2005;18:1169-75. doi:10.1002/poc.965.

[27] Manolova Y, Kurteva V, Antonov L, Marciniak H, Lochbrunner S, Crochet A, et al. 4Hydroxy-1-naphthaldehydes: proton transfer or deprotonation. Phys Chem Chem Phys 2015;17:10238-49. doi:10.1039/C5CP00870K.

[28] Hansen PE, Thiessen H, Brodersen R, Lempert K, Møller J, Folkers K, et al. Bilirubin Acidity. Titrimetric and 13C NMR Studies. Acta Chem Scand 1979;33b:281-93. doi:10.3891/acta.chem.scand.33b-0281. 
Highlights:

- Two possible mechanisms for controlling the tautomerism in Sudan I are discussed.

- The availability of additional $\mathrm{OH}$ group changes the tautomeric equilibrium upon deprotonation.

- The addition of sidearm, which easily protonates, control the tautomeric process through $\mathrm{H}$-bonding. 